\title{
Internal Temperature Measurements by X-Ray Diffraction on Magnetic Nanoparticles Heated by a High-Frequency Magnetic Field
}

Stéphane Faure, ${ }^{*}{ }^{\dagger}$ Nicolas Mille, ${ }^{*}{ }^{\dagger}$ Sumeet S. Kale,${ }^{\dagger}$ Juan M. Asensio,${ }^{\dagger}$ Julien Marbaix, ${ }^{\dagger}$ Pierre Farger, ${ }^{\dagger}$ Dragos Stoian, ${ }^{\dagger}$ Wouter van Beek, ${ }^{\star}$ Pier-Francesco Fazzini, ${ }^{\dagger}$ Katerina Soulantica, ${ }^{\dagger}$ Bruno Chaudret ${ }^{\dagger}$ and Julian Carrey, ${ }^{*}$

† Laboratoire de Physique et Chimie des Nano-Objets (LPCNO), Université de ToulouseINSA-UPS, 135 Avenue de Rangueil, F-31077 Toulouse, France.

$\$$ Swiss Norwegian Beamlines - ESRF - 38043 Grenoble, France.

\section{Supporting Information}

\section{Synthesis of $\mathrm{Fe}(0)$ Nanoparticles}

$\mathrm{Fe}(0)$ nanoparticles were synthesized by following a method reported by our group ${ }^{1,2}$. In a typical synthesis, $2.62 \mathrm{mmol}$ of PA (666.4 g) and $2.00 \mathrm{mmol}$ of HDA (483.0 $\mathrm{mg})$ were dissolved in the mesitylene and added to a green solution of $1.00 \mathrm{mmol}$ of $\left[\mathrm{Fe}\left\{\mathrm{N}\left(\mathrm{SiMe}_{3}\right)_{2}\right\}_{2}\right]_{2}$ $(753.2 \mathrm{mg})$ in $10 \mathrm{ml}$ of mesitylene in a Fischer Porter bottle in the glove box. The Fischer Porter bottle was then pressurized with hydrogen gas ( 2 bar) and placed in an oil bath at $150{ }^{\circ} \mathrm{C}$ for 72 $\mathrm{h}$ under vigorous magnetic stirring $(400 \mathrm{rpm})$. After $72 \mathrm{~h}$ the reaction was stopped, and the NPs were recovered by decantation assisted by a magnet. The NPs were further washed with toluene $(3 \times 10 \mathrm{~mL})$ and THF $(3 \times 10 \mathrm{~mL})$ and dried under vacuum to give ca. $100 \mathrm{mg}$ of $\mathrm{Fe}(0) \mathrm{NPs}$ as a powder which contained $75 \%$ of $\mathrm{Fe}$ as determined by TGA (Yield in $\mathrm{Fe}-67 \%$ ). TEM structural analysis shows well dispersed NPs with a size distribution of $12.7 \pm 1.3 \mathrm{~nm}$ (Figure SI 1).
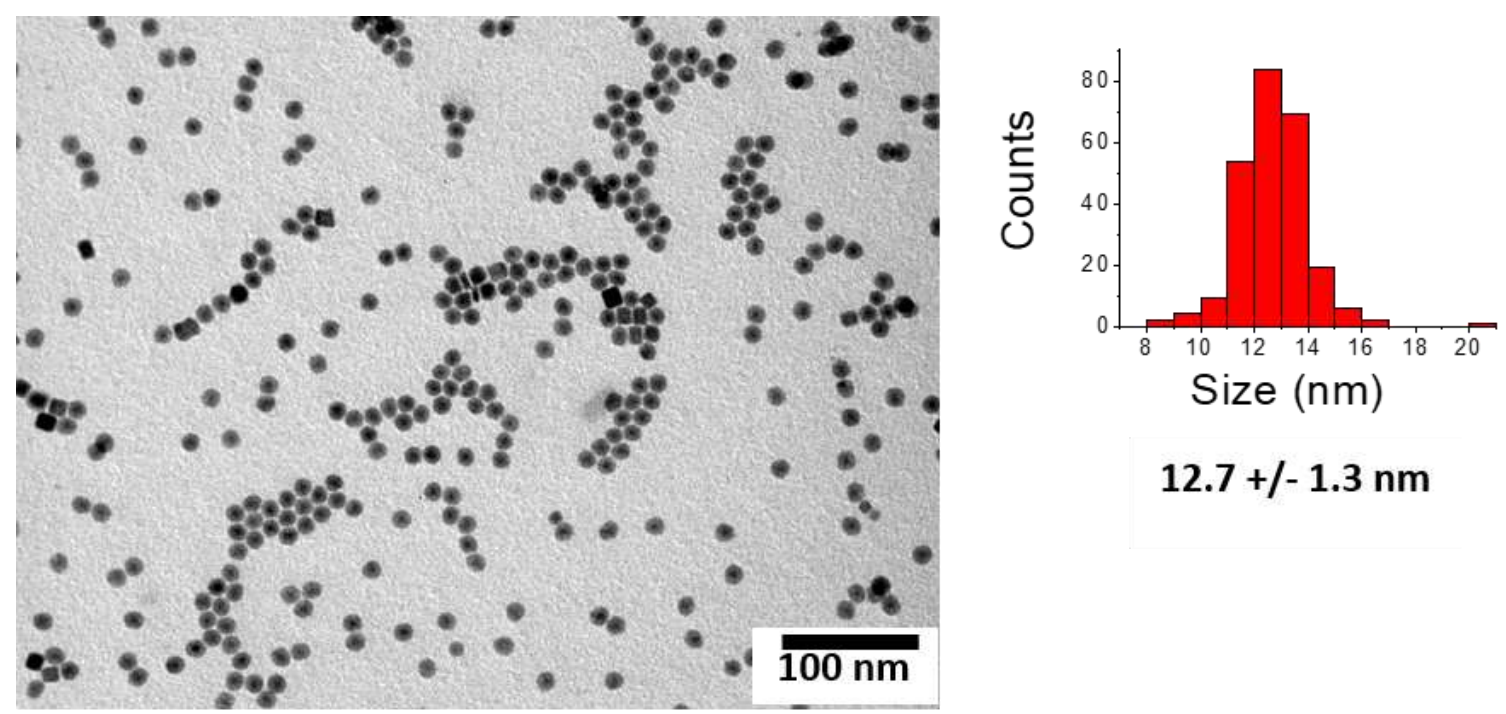

$12.7+/-1.3 \mathrm{~nm}$

Figure SI 1. TEM structural analysis of iron(0) nanoparticles and size distribution of the iron(0) core. 


\section{Synthesis of Fe2.2C NPs}

Iron carbide NPs were prepared through carbidization of preformed $\mathrm{Fe}(0) \mathrm{NPs}^{42}$. In a typical experiment, in the glove box, $\mathrm{Fe}(0) \mathrm{NPs}(50 \mathrm{mg}$, ca. $0.67 \mathrm{mmol}$ of iron) and palmitic acid $(50 \mathrm{mg})$ were dispersed in mesitylene $(10 \mathrm{~mL})$ in a Fischer Porter bottle. The mixture was then pressurized with $\mathrm{CO}$ and $\mathrm{H}_{2}$ (2 bars of each), and was allowed to stir (700 rpm) at $150{ }^{\circ} \mathrm{C}$ for $120 \mathrm{~h}$. At the end of the reaction, the NPs were recovered by decanting the supernatant solution with the help of a magnet. The recovered NPs were washed with toluene $(3 \times 5 \mathrm{~mL})$ and dried under vacuum to give ca. $50 \mathrm{mg}$ of $\mathrm{Fe}_{2.2} \mathrm{C}$ NPs as a powder which Fe content determined by TGA was of ca. $70 \mathrm{wt} \%$ in all the cases. (Yield in Fe $-84 \%$ ). The NPs are well dispersed with a size distribution of $14.6 \pm 1.1 \mathrm{~nm}$ (Figure SI 2). The heating power value was ca. 2000 $\mathrm{W} \cdot \mathrm{g}^{-1}$ at $47 \mathrm{mT}$ and $100 \mathrm{kHz}$ frequency in solution.

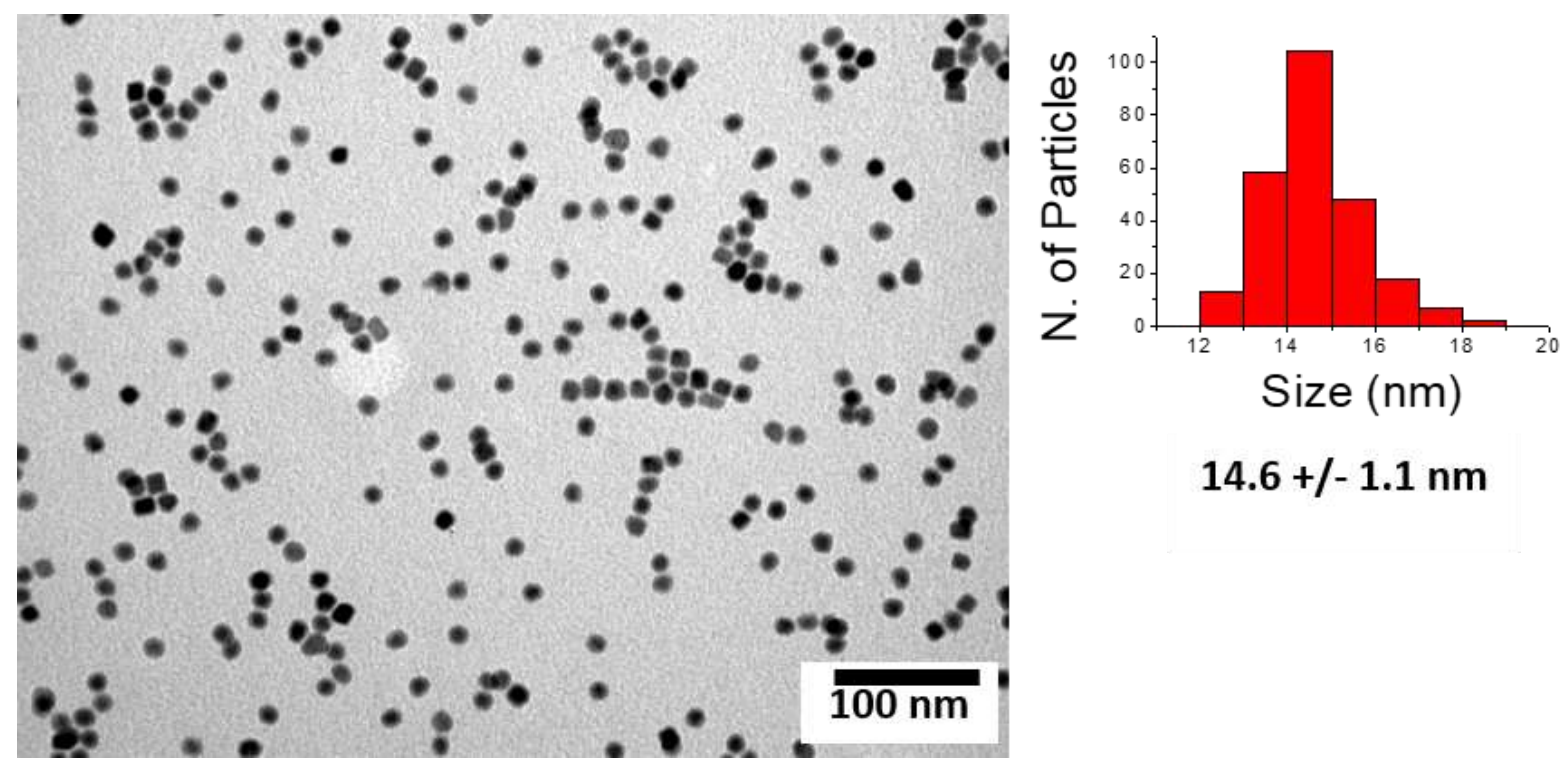

Figure SI 2. TEM structural analysis of iron carbide nanoparticles and size distribution of the core.

\section{Synthesis of Ni doped SiRAlOx}

The catalyst (10 wt\% of $\mathrm{Ni}$ supported on SiRAlOx) was prepared by decomposition $\mathrm{Ni}(\mathrm{COD})_{2}$ on the support at $150{ }^{\circ} \mathrm{C}$. Typically, SiRAlOx $(1 \mathrm{~g})$ was added to a yellow solution of $\mathrm{Ni}(\mathrm{COD})_{2}(520.6 \mathrm{mg})$ in mesitylene $(20 \mathrm{ml})$ in the glove box. The resulting mixture was sonicated for $20 \mathrm{~min}$. and then stirred under Ar at room temperature for 30 minutes. The solution was then refluxed at $150^{\circ} \mathrm{C}$ for $1 \mathrm{~h}$ under rigorous stirring $(700 \mathrm{rpm})$. At the end of the reaction, the Ni supported on SiRAlOx was recovered by decantation of supernatant solution, washed with THF ( $5 \mathrm{ml}$ x 3 times) and dried under vacuum. Yield ca. $1 \mathrm{~g} \mathrm{Ni} / \mathrm{SiRAlOx}$. Metal content determined by ICP (wt\%): Ni, 9.86 .

\section{SI References}

[1] Bordet, A. ; Lacroix, L.-M.; Fazzini, P.-F.; Carrey, J.; Soulantica, K.; Chaudret, B. ; Magnetically Induced Continuous CO2 Hydrogenation Using Composite Iron Carbide 
$50 \quad$ Nanoparticles of Exceptionally High Heating Power, Angew. Chem., Int. Ed. 2016, 55, 1589415898. https://doi.org/10.1002/anie.201609477.

[2] Lacroix, L.-M.; Lachaize, S.; Falqui, A.; Respaud, M.; Chaudret, B.; Iron Nanoparticle Growth in Organic Superstructures, J. Am. Chem. Soc. 2009, 131, 549-557. https://doi.org/10.1021/ja805719c. 